\title{
ECOLOGICAL FEMINISM ISSUES DEPICTED IN MOANA'S SCREENPLAY BY JARED BUSH
}

\author{
Susi Ambarwati ${ }^{1}$, Radius Setiyawan ${ }^{2}$, Pramudana Ihsan ${ }^{3}$ \\ Muhammadiyah University of Surabaya, susiambar80@yahoo.co.id
}

\begin{abstract}
The purpose of this research is to reveal whether Moana's Screenplay by Jared Bush can be considered as an eco-feminism reading or not. To prove this hypothesis, the researcher analyzes Moana's Screenplay through find out the characteristics of the main character that reflect ecological feminism and reveals the relationship between man, woman, and nature in Moana's screenplay using eco-feminism perspective. The researcher uses descriptive qualitative methods in analyzing the data. The researcher found that eco-feminism issues were clearly shown in this screenplay. First, the main character in Moana's Screenplay was not described as a weak woman but she showed the characteristics of leadership, ambitious, and courageous where these characters usually owned by man. She was described as a woman who loved their people and the environment which is a reflection of ecological feminism. Second, the relationship between man and woman was illustrated that male characters dominated woman both verbally and mentally. Third, regarding the relationship between man and nature, it was found that nature was dominated because man saw nature as a resource to meet human needs. Finally, related to the relationship between woman and nature, it was revealed that woman was closer to nature than man so they can live in harmony.
\end{abstract}

Keywords: Eco-feminism, Characterization, Man and Woman, Man and Nature, Woman and Nature.

Historically women are the first oppressed group and the issue of oppression of women is the most widespread (Alison and Paula in Tong, 2009: 49). The oppression of women is often associated with the neglect of women's rights, those oppression often lead to discrimination, exploitation, violence, injustice, and others. Based on the arguments of the theorists, feminisms criticism focused on the system of gender-based inequality and its relation to the other forms of oppression based on sexuality, class, and race (Paludi, 2010: 22). Woman is treated as second class and do not deserve to have the same treatment enjoyed by men (Tong, 2009: 81). It means that woman is considered to be at the lowest level. This is what drives feminists to make a movement and the main purpose of feminism is to fight for the humanity of women to be equal with man.

Eco-feminism is a branch of feminism theory that examines the connection between woman and nature (d'Eaubonne in Tong, 2009: 242). Some pioneers of theory of eco-feminism believe that there are relationships between the environmental damaged and woman oppression. Based on Warren's statement (Tong, 2009:238) hierarchical, dualistic, and oppressive thinking have damaged both nature and woman. Warren stated that the hierarchical view of nature has affected women. It can be said that woman can feel the bad reality felt by nature.

Eco-feminism claims that women are culturally bound to nature, this claims give rise to perspective that there are conceptual, symbolic and linguistic linkages between 
feminist and ecological issues (Tong, 2009: 237). Woman is unconsciously "naturalized" and nature has been "feminized". The term of "naturalized" is when woman is pictured as animals. While the term of nature has been "feminized" is when nature is mined, dominated, and conquered by man (Warren in Tong, 2009: 238). The domination performed by man against nature, in other words can also be done to woman (Warren in Tong, 2009: 238). That is to say, if man is given authority over nature, then he not only has control over nature but also with woman, so that whatever man do to nature, it is also possible he may do to woman.

In male domination society, society places a priority on male lineage. There is a clear discrimination between man and woman, and placement of a clear position as well, in which man and is upper class and woman is lower class (Gaard, 1993: 1). It implies that man has a higher position than woman. Without the logic of domination, the difference is only noble diversity,but with it differences become the basis for domination and subordination, inferiorisation and marginalization (Warren, 1997: 20). It means the existence of logic domination causes many problems happened to woman, such as marginalization, gender discrimination, stereotype and violation. Rosemary Radford Ruether state (Tong, 2009:238):

"Women must see that there can be no liberation for them and no solutionto the ecological aims within a society whose fundamental model of relationships continues to be one of domination. They must unite the demands of the women's movement with those of the ecological movement to envision a radical reshaping of the basic socioeconomic relations and the underlying values of this [modern industrial] society"

It means that woman and nature must reunite together in order to be liberate from man. Many women have struggled with many ways to fight violence to get freedom; one of them is through literary works, such as novels, poetry, and screenplay.

Moana's screenplay shows that there is close relationship between woman and nature. This screenplay pictures Moana who loves the environment and her strong desire to protect nature. Therefore, Moana's character strongly shows the idea of ecological feminism. The message shows the figure of a woman who is responsible for the nature of hierarchical culture, in which the male characters are more dominant or wants to rule. Furthermore the researcher finds there is no one has discuses eco-feminism in Moana's Screenplay. That is why the researcher is interested in conducting the study to find out ecological feminism issues as expressed in screenplay. The objectives of this research are to know the characteristics of the main character in Moana's screenplay by Jared Bush that reflect ecological feminism, and to know ecological feminism issues depicted in Moana's screenplay by Jared Bush. 


\section{RESEARCH METHOD}

This research was a qualitative research because the data presented in Moana's screenplay in the form of the dialogue, statement and sentence. According to Creswell (2009: 173) qualitative research depend on text and image data, have unique steps in data analysis and can be draw on different strategies of research. The object of the study is presented more in words rather than in numbers. Then, in this research, the words, sentences or statement related to the eco-feminism issues in Moana's screenplay become the data of the study.

By understanding the method, qualitative research method was used by the researcher to analyze the data. According to Hancock (2009: 6) qualitative research focuses on reports of experience or on data which cannot be adequately expressed numerically, in contrast quantitative research uses statistical techniques that allow us to talk about how likely it is thatsomething is "true" for a given population in an objective or measurable sense. Thus, the researcher concluded that qualitative method is the most appropriate technique since the data of this research are represented in the forms of words, sentences, statement or cannot expressed numerically that fulfill the categorization for the analysis.

\section{RESEARCH FINDINGS}

The results of this research prove that Moana's screenplay by Jared Bush can be considered as eco-feminism reading. This research reveal that the main character of Moana's screenplay by Jared Bush reflect ecological feminism and ecological feminism issues are clearly depicted in this screenplay.

First, it can be seen that the main character does not described as weak and passive woman like the description of woman in general. The main character's characteristics reflect ecological feminism. Moana describes as a character that possesses characteristics of leadership, ambitious and courageous. The term leadership means the ability to be a leader or the qualities a good leader. Leadership means the ability that a person possesses to be a leader or has the qualities of a good leader. Moana is portrayed as a leader. Her leadership characteristic can be seen when she is being trained by her father as the next chief in her Island to replace her father's position. She always help their people, it can be seen when she help the villager to fix a leaky roof. She also gives solution to the villager who complains about the rotten coconut harvest. When the other villager complains about the little fish catch, she also tries to give solution to the villager to fishing in the other part of the Island.

The other scene that shows Moana's leadership characteristic is when she realize that her Island suffered because of someone steal the heart of Mother Island, he is Maui. They believed that heart has the power of creating life. Maui's action gave birth to the darkness which began spread to her island, drawn the island and case away the fish. She tries to convince her father that the only way to save their Island is by restoring the heart of Mother Island. Furthermore, she also successes to make a deal with Maui to sail the ocean together and restores the heart. According to Socrates (in Gini and Green, 2013: 23) the trait of leadership is intelligence, and always do the right things for the right reason. Based on the 
discussion above it can be conclude that Moana shows the trait of being a good leader that is always help people, intelligence, able to make a deal with the other. The other characteristic owned by Moana is ambitious. Ambitious is having or showing strong desire and determination to successes. It is a feeling or belief that he or she can do something well or success in something. Do something with passion, without any doubt despite many obstacles encountered. Moana was encouraged by her father and mother to learn to be the next leader to replace her father position as a chief in their Island. Moana learns everything about life on her island, but she finds herself constantly drawn to the ocean. In the beginning of screenplay shows that several times Moana tries to go to the ocean and every time she tried to approach the ocean, her parents brought her back and reminded her of her duties and her people were the most appropriate place where she should be. According to King (2013: 8-10) ambitious is characterized by the presence of rebellion, desire and efforts achieve a certain goal. Because of her ambitious to help her people and save the Island makes her do some efforts. Thus, it can be said that Moana has a strong desire to achieve her goal and she shows her effort to achieve her goal. Moreover, she rebel her father role of not approach the ocean. It implies that she is a character who has a strong ambitious.

The last characteristic of Moana that reflect ecological feminism is courageous. Courage means the ability to do something that frightens one. There are several scenes in this screenplay that shows Moana's courageous. It can be seen when she tries to reclaim the heart that have been stolen by the pirates who also wanting the heart of Mother Island, that is Kakamora. Even though Maui refuse to take back the heart but Moana courageously battle with those pirates and take back the heart. The other scene that shows Moana's courageous is when she helps Maui to take back his hook from Tamatoa in the realm of Monster. Because her courage to trick Tamatoa they can escape from Tamatoa. Moana describes as a brave woman, in the first time of their effort to pas the Lava Monster they failed and it makes Maui leave Moana alone. Courageously Moana tries to pass the Lava Monster using her trick. According to some scholars courageous is often associated with self-sacrifice, the presence of bravery, risk taking, and having noble goals (Rate, 2007: 80-82). Moana clearly shows the traits of courageous character that is bravery, risking her life, and pursuing a noble and courageous purpose. Based on the previous discussion the main character in Moana's Screenplay by Jared Bush described as an easy sympathetic character and empathy for each other and the environment. So, the researcher conclude that the main character in Moana's Screenplay by Jared Bush reflect ecological feminism.

Second, ecological feminism issues depicted in this screenplay can be seen through the relationship between man and woman, man and nature, and woman and nature. The first issues that depict ecological feminism is the relationship between man and woman, the male characters in this screenplay shows domination attitude. Moana's father shows this attitude. From the beginning, Moana's father wants her become a chief like him. He showed Moana that the right place for her was as a Chief for her people and vowed to protect her people as all the previous chiefs had done. No one questioned that she will lead or doubt that she should lead. So, it is obviously that her father has right over her. She must obey her father's order. She was not given a chance to convey what she wants to be. This supported by Ruether's statement in Gaard (1993: 273) that natural 
damage by humans and women's oppression were enacted and continued by social structure that allowed one group to dominate the other group. She added that man is considers superior toward woman. So, from the beginning it has been established that man is a superior over woman. There is scene when Moana suggest the villager to fishing beyond the reef and at the same time her father oppose directly her suggest and said that no one allowed to goes beyond the reef. Although Moana is being trained as a chief, but her father keeps showing his power. As stated by Birkeland in Gaard (1993: 21) the fact is that men of all classes still use and take power over women even within their classes, such as work places, political parties, or family structures, especially power in public areas. When her father said that "no one goes beyond the reef" it means that only him that allowed to go beyond the reef, because he feels that he knows better which one is the best for their people than Moana. Moreover Moana is a woman and go to the ocean is dangerous for her. The other dominant attitude showed by Maui. Hierarchical mindset which is held up by Maui places him above the others. He feels superior toward Moana, because he is a man, while Moana is a woman. Maui shows a dominant attitude such as his superior attitudes and his desire to increase his strength. . Socially, man is freer to actualize themselves than woman (Merchant, 2005: 201). Because of this term, then the natural roles of women will form by itself, that is, woman is more passive and it enables man to dominate woman. There is scene when Maui calls Moana as "Princess" because she wears a dress. A princess represents a woman's gender, in which woman's duty common with staying at home. Maui here refers to social roles of woman, who always on the "home" side and it is very different with man which is more get freedom. So Maui tells Moana that she never becomes a sailor like she wants to be. Moreover Maui also calls Moana as "the other chicken" it means Maui equals Moana with the chicken. Eco-feminism reveals the form of dualism by looking at traits such as feminization and naturalization or "making women into animals terms" have proved the domination of women, animals and the earth (Gaard, 1993: 5). Because the chicken in this Moana's screenplay is genderless, or it is not identified as man or women, so it is categorized as nature. When a woman associated as nature it means those woman accept oppression. The other Maui's attitude that showed domination is when he mentioned Moana about her duties as a woman, she mentioned about "living in the village, kissing babies and things" where it is commonly done by a woman. So he doubts why her people sent her to restore the heart of Mother Island where that duty did not fit her nature as a woman. Ecofeminism sees there is connection between exploitation of woman and nature. One of exploitation toward nature is all treatments that indicate natural control. When woman receives unfair treatment then it is reminiscent of the treatment of animal. So, if a woman controlled by man it implies this woman is equal with nature. As Adams argues once a woman's body is objectified, women are seen as less than human, and are considered more appropriate as objects to be used or utilized (in Gaard, 1993:300). There is scene when Maui uses Moana as "bait" to attract the monster out. He never considers Moana's feeling, he always makes decision by himself, he does whatever he wants. Because he is a man and feels superior toward Moana, he becomes more arrogant and pretentious. His high ego makes him feel superior to others. According to Plant in warren (1997: 129) looking at feminist critiques of human relationships and placing them side by side with the 
analysis of human and nonhuman relationships, shows that both women and the earth have been regarded as objects of some selfishness. Because man view woman as their inferior so woman deserve to accept domination treatment.

The second issues related to the relationship between man and nature. Male domination of the natural environment has become one of their strengths. The male characters in this screenplay have a constant that needs to show their male qualities and desires as if they were superior to the environment surrounding them. Different perspectives or point of view or knowledge of a person brings different understanding and attitudes toward nature and causes disputes among themselves. But above all, men's opinions about nature differ from women, they argue that the environment is profitable and they have power over the environment. Later, this opinion makes men do some actions against the environment that often brings adverse consequences for the environment itself. In Moana's screenplay, it is shown by Maui. As a man who has instinct to rule over everything, he is not aware of the consequences that will be caused by his actions. Greta Gaard (1993: 1) argues that the main cause of problems concerning women and nature is male domination. Man is often viewed as superior to women in society, as well as culture is often considered superior to nature. In general, human being see themselves superior to the natural environment and patriarchy is seen as "the villain behind the ecological crisis" (Plumwood, 1993: 11). The scriptwriter describes the Mother Island with stolen heart turned into a lava and ash desert. It turned into an empty island and took a very long time to heal. It indicates that what man do toward nature is bad, while woman do is good (Merchant, 2005: 204). Li stated in Gaard (1993: 272), ecologists believe that there are similarities between women and nature, such as passive attitudes and life-giving care this makes them equally vulnerable to male domination. There are scenes that show man's treatment toward nature. When the villager jokes about cooking the chicken with disability and Maui's statement about he would love the chicken inside his belly. It means that man only sees chicken as an animal which it creates to provide human needs. The role of women and animals in a patriarchal society is to serve. Women and animals are as used. They were created as a symbol to justify and maintain the superiority of men or be caught as servants to provide and entertain (Gaard, 1993:61). Both of them rather see the chicken as food than as a "companion" like Moana does. Because Maui and the villager assume that nature or animal as a sources which creates to provide human needs, so they see that chicken just as "a pieces of meat" and nothing more. It is different with Moana perspective, she considers that chicken as her companion than just an animal.

The last issues related to ecological feminism is the relationship between woman and nature. In this screenplay the main character grows in a natural environment where she has a close relationship with nature. She felt connected to the natural environment around her. She has a very strong opinion about following the call of nature. From an eco-feminist perspective, this is seen as an important idea because the relationship between the main character and nature is at the spiritual level. Spiritually living with the understanding that one is inextricably linked to all creation, all visible and invisible powers (Smith in Warren, 1997: 31). Eco-feminists believe that woman has a closer relationship with nature than man. Woman and nature build a harmonious world in which they 
interconnect and interact to one another. In addition, in many literary works, some people often compare nature with mothers. In China, the Yellow river is often associated with mother. While in Moana's screenplay, there is an island which is believed as mother of Island. The pronoun "mother" here clearly illustrates that the mother island is depicted as a woman. It uses pronoun which refers to woman. She has a great heart that believed to be able to create life. And with generously she shared that power with the world and created life for it. Tong said in her book that some eco-feminist construct idea that nature as a benevolent female or mother who give birth and nurture their children generously (Tong, 2009: 240). This reflects that nature similar with woman who gives birth and generously of her bounty to their children. Nature gives birth to animal and plant, while women give birth to their children. It means that both of them are able to give life. In the view of eco-feminist women are often associated with nature, and it makes woman more sensitive to the environment and living things. Moana is a very strong figure with the idea of eco-feminism. This is showed when Moana trying to save a baby sea turtle, she makes a path and protects the baby sea turtle from bird that trying to kill it. There are scenes that give an idea that woman's view towards nature different with man's view. That is an apology of Moana to the pig when she tasted of a bowl of pork, and a villager who joked about eating disability chicken. Moana states that everyone and everything have a purpose, so the chicken cannot be used as food just because its purpose has not been revealed. Creating nature as a partner, it might allow for personal or deep (but not necessarily spiritual) relationships with nature and creates feelings of sympathy for non-human beings and for people who are different from us by sexual, racial, or cultural (Merchant, 2005: 197). Seen from an eco-feminist perspective, the main character believes that humans are naturally related to nature not only within but also outside. Therefore, man has no right to harm or act higher toward nature. In this screenplay s also howed that animal was chosen as a companion character. The other woman character that showed her close relationship with nature is Moana's gramma, she is a woman who has a stingray tattoo on her back, she often dance in the water with stingray under the water around her. This scene shows that gramma seems has close relationship with the stingray. She said that when she dies she will come back as one of those stingrays. It seems that she become part of one of them. The main character identifies herself with the natural environment and therefore she feels concerned with the act of stealing the heart of Mother Island to gain respect from others. Without her heart Mother Island began loses her true identity and transform into terrible monster. It describes the oppression and violations committed against nature as well as that which will happen to women in general, women will also feel crushed.

Even though in the beginning the one who responsible to restore the heart of Mother Island is Maui but the one who success restore the heart of Mother Island is Moana. As stated by Li in Gaard's book, the relationship between woman and nature gives woman a special interest in the healing of alienation between man and nature and, finally, in solving current environmental problems (1993). They believe that traditional systems of sex or gender have a significant impact on current environmental problems. Moreover, many eco-feminists accept the ancient perception of the similarity between woman and nature as self-evident explanations for the relationship between these two forms of oppression. 
Based on an ecological feminism perspective, when woman and nature help each other, they will both be liberating from the male domination society. Moana and the natural surroundings her are a very good example of this claim. When they help each other, they have more strength and courage to conquer man. In the end, both of them can overcome man and capitalism and can free themselves from male domination and exploitation.

\section{CONCLUSION}

In this chapter, the researcher draws some conclusions from this research which analyzed ecological feminism in the Moana's screenplay (2016) written by Jared Bush. This research uses descriptive qualitative method using the theory of ecological feminism by Karen J Warren.

In this screenplay pictured the exploitation that is always done by man. The interesting about the main character in screenplay is about the depiction of woman who is different from the images of woman in general. Moana is not portrayed as weak, passive, and always need the help of a man. But in this screenplay, Moana is portrayed has leadership, ambitious, and courageous characteristic in which those characteristics usually owned by man. Moana is describes as woman who loves her people and the environment which is a reflection of ecological feminism.

Viewed from the perspective of ecological feminism, the relationship between man and woman in this screenplay, it is illustrated that man dominate woman both mentally and verbally. Because a woman is considered weak, so man feels superiority toward woman. Being observed from the relationship between man and nature, man assumes that both woman and nature are created to meet man's need, so that man has right to dominate. While seen from the relationship between woman and nature, based on ecological feminist perceptions, woman is considered close to nature. Naturally, woman knows how to live in harmony with nature. Both of them describe being able to live in harmony with nature. This study shows that Moana's screenplay can be analyzed using ecological feminism theory. This screenplay also shows that woman has an important role in protecting nature. Finally, ecological feminists believe that building sustainable relationships is a solution where man, woman and nature can live together harmoniously.

\section{REREFENCES}

Creswell, J. W. (2009). Research Design Qualitative, Quantitative and MixMethods Approaches (3rd Ed.). London: Sage publication.

Gaard, Greta. (1993). Ecofeminism: Women, Animals, Nature. Philadelphia: Temple University Press.

Gini, Al and Green, Ronald M. (2013).10 Virtues of Outstanding Leaders: Leadership and Character, First Edition. Vol. 3 (6): pp. 5.

Hancock, B. et al. (2009). An Introduction to Qualitative Research. Yorkshire: The NIHR RDS East Midlands.

King, William C. (2013). Ambition, a History from Vice to Virtue. London: Yale University Press. 
Merchant, Carolyn. (2005). Radical Ecology: The Search for a Livable World. New York: Routledge.

Plumwood, Val. (1993). Feminism and the Mastery of Nature. London: Routledge.

Rate, Christopher R. et. al. (2007). Implicit Theories of Courage. The Journal of Positive Psychology: Dedicated to Furthering Research and Promoting Good Practice.Vol. 2 (2). pp: 80-98.

Tong, Rosemarie Putnam. (2009). Feminist Thought: A More Comprehensive Introduction. United States: Westview Press.

Warren, Karen J. (1997). Ecofeminism: Woman, Culture, Nature. United States: Indiana University Press. 